\title{
A Review on Cell Cycle Checkpoints in Relation to Cancer
}

\author{
Swarup K Panda ${ }^{1}$, Subhashree Ray ${ }^{2}$, Sarthak R Nayak ${ }^{3}$, Sudeshna Behera ${ }^{4}$, Sangeeta S Bhanja ${ }^{5}$, Viyatprajna Acharya ${ }^{6}$
}

\begin{abstract}
Genomic integrity is required to maintain long life and prevent diseases associated with genomic instability such as "cancer." The cell cycle is a compilation of well-organized, sequential molecular events, that lead to succession of DNA replication and segregation of replicated chromosomes. Cell cycle checkpoints are the strict regulatory mechanisms that monitor the order, integrity, and fidelity of the main events of the cell cycle. These include growth up to the acceptable cell size, replication, and integrity of the chromosomes, and their accurate segregation in due course of mitosis. Many of these mechanisms are highly conserved, while other studies on higher organisms have shown to control alternative cell fates with a significant impact on tumor suppression. Here, we take into consideration these different checkpoint pathways in a cell cycle and the consequences of their dysfunction on the fate of a cell.
\end{abstract}

Keywords: Cancer, Cell cycle, Checkpoint, DNA damage, Genomic instability, Mitosis.

The Journal of Medical Sciences (2019): 10.5005/jp-journals-10045-00138

\section{INTRODUCTION}

A recent in-depth view of cell cycle regulation and cancer has provided novel samples of research at the "Frontiers of Science." However, the number of foremost revealing information about both the topics has been derived from the intersection of these two fields. ${ }^{1-5}$ This review intends to introduce the basics of the cell cycle and its regulation at different checkpoints in relation to cancer. Cancer is broadly a result of unchecked cell multiplication due to abnormal activity of varied cell cycle proteins; therefore, cell cycle regulators are considered attractive targets in cancer therapy. Many cancers are uniquely linked with these proteins and are therefore selectively sensitive to their inhibition. ${ }^{6}$ After a long run of research on the physiological functions of cell cycle proteins and their relevance for cancer, these data recently got converted into the first approved cancer therapeutics, targeting the regulator of cell cycle. ${ }^{7}$ Here, we are reviewing the role of cell cycle proteins in cancer, only on those proteins that directly regulate cell cycle progression along with cyclin-dependent kinases (CDKs) and their transcriptional regulatory mechanisms.

"Cell cycle" is a highly integrated process that regulates the timing and frequency of deoxyribonucleic acid (DNA) duplication and cell division. As a biological concept, the cycle of events that a cell undergoes from one division to subsequent is called "the cell cycle." The contents of the cell must be accurately replicated during this period. In other words, the cyclic path of cellular events is known as "the cell cycle."

The cell cycle is a 4-stage process consisting of gap 1 (G1), synthesis (S), gap 2 (G2), and mitosis (M) phase ${ }^{8}$ (Fig. 1).

The $G_{1}$ phase/pre-synthetic phase begins immediately after the mitotic division, where new organelles are formed along with proteins and ribonucleic acid (RNA) synthesis. By the end of the $G_{1}$ phase, the cell attains double the size. This is followed by the $S$ phase/synthetic phase in which, a duplicate copy of every chromosome is formed by doubling the amount of DNA in the cell, along with the synthesis of RNA and proteins. In the $G_{2}$ phase/premitotic phase, the cell gets prepared to start mitosis, where DNA synthesis stops, but the synthesis of RNA and protein continues. Finally, in the $\mathrm{M}$ phase/mitosis, the cell undergoes nuclear as well

\footnotetext{
${ }^{1-6}$ Department of Biochemistry, IMS and SUM Hospital, Siksha ' $O$ ' Anusandhan University, Bhubaneswar, Odisha, India

Corresponding Author: Swarup K Panda, Department of Biochemistry, IMS and SUM Hospital, Siksha'O'Anusandhan University, Bhubaneswar, Odisha, India, Phone:+91 7978334739, e-mail: ssom62854@gmail.com How to cite this article: Panda SK, Ray S, Nayak SR. A Review on Cell Cycle Checkpoints in Relation to Cancer. J Med Sci 2019;5(4):88-95.

Source of support: Nil

Conflict of interest: None
}

as cellular division, resulting in two daughter cells containing the same amount of genetic material as that of the parent cell. ${ }^{9,10}$

\section{Stages of Mitosis (Fig. 2)}

The mitosis/M-phase consists of four phases. The first phase is prophase, where 46 replicated chromosomes condense with two sister chromatids each, along with the formation of spindle fibers and rupture of the nuclear membrane. It is followed by metaphase where chromosomes with attached spindle fibers, move towards the middle (i.e., metaphase plate) of the cell. Then anaphase comes into play, where centromeres divide to convert each sister chromatid along with chromosomal migration to the two opposite ends of the cell. Finally, the telophase brings the end of mitosis, where chromosomes unwind, spindle fibers break down with reformation of the nuclear membrane as well. It is followed by cytokinesis, where cell membrane contracts, ultimately resulting in two daughter cells with 46 chromosomes each. ${ }^{9,10}$

\section{Control of Cell Cycle}

Internal and external signals: either stimulate or inhibit a metabolic event. Internal signals, such as a small cell with inadequate availability of nutrients, incomplete DNA synthesis, and incomplete attachment of kinetochore, all these factors may act as "stop signal." On the other hand, high levels of cyclin with a stable concentration of mitosis-promoting factor (MPF), complete DNA replication, and attachment of all sister chromatids with kinetochore spindle fibers act as "start signal." 


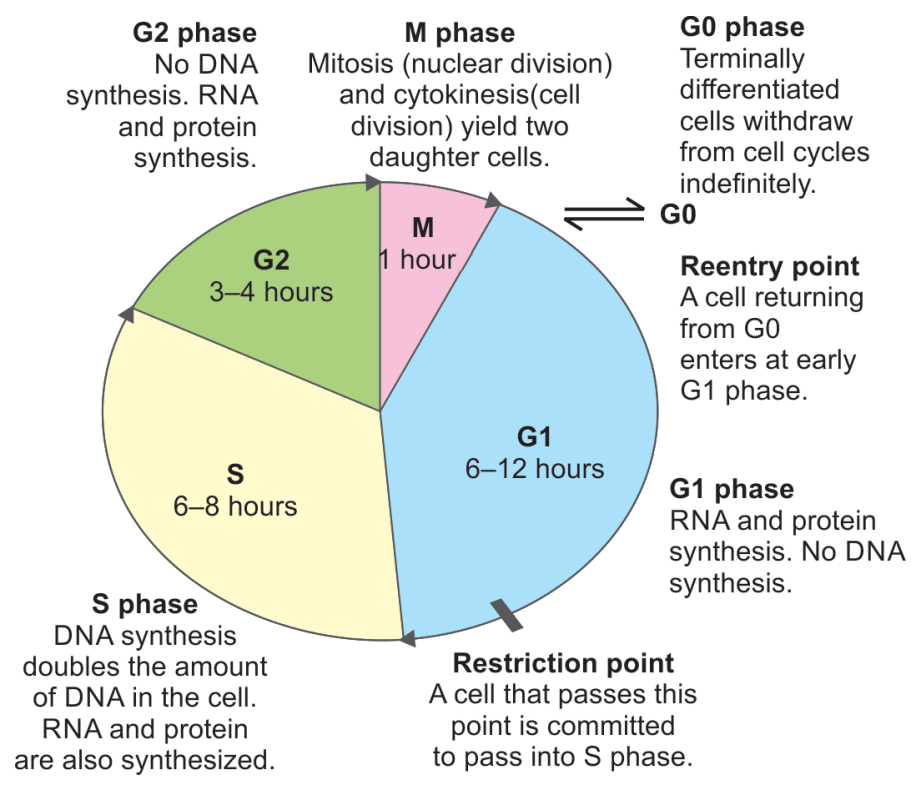

Fig. 1: Eukaryotic cell cycle

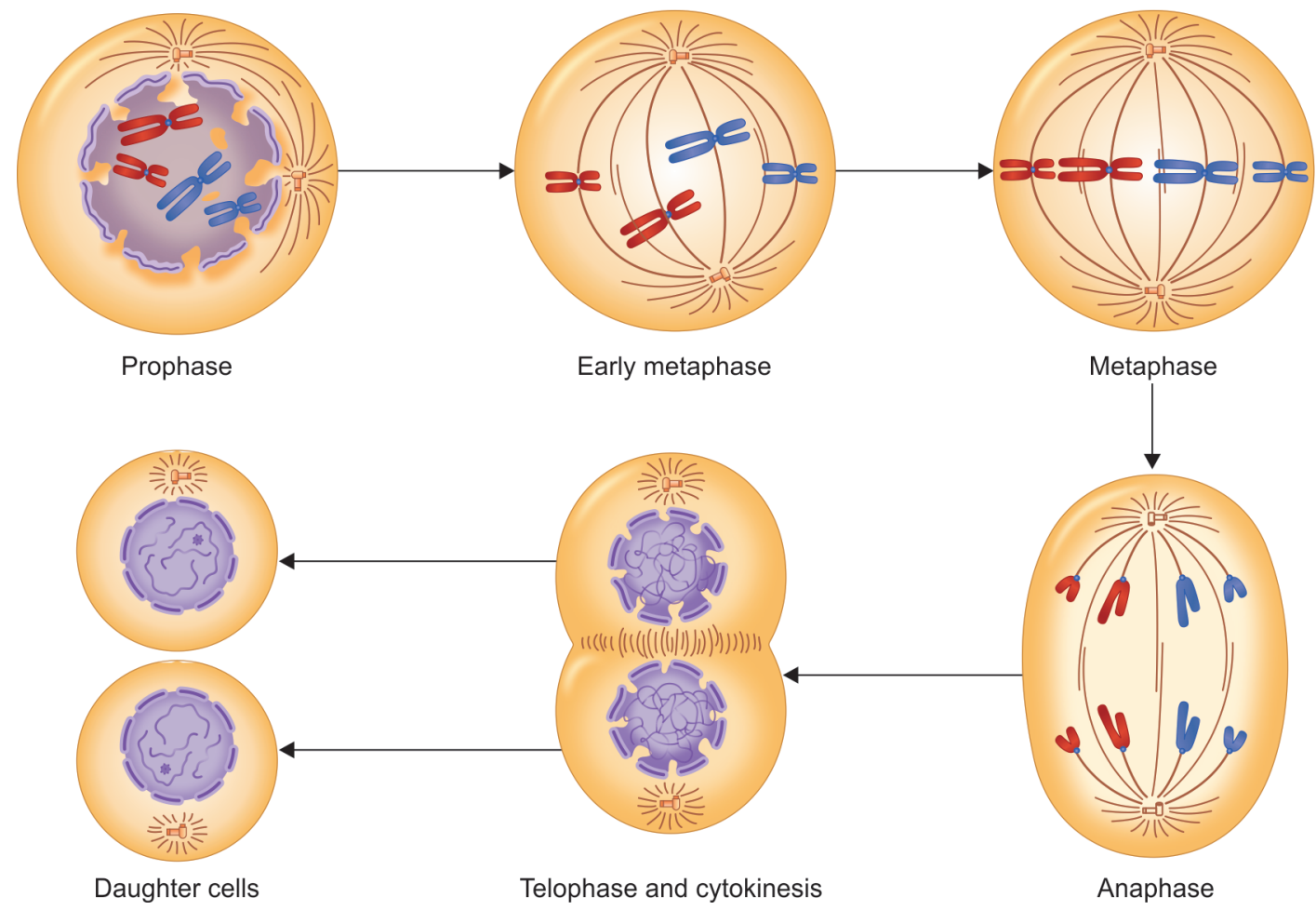

Fig. 2: Stages of mitosis

Similarly, external signals, such as the absence of adequate space to grow (in vivo), no proper anchorage in Petri dish (in vitro) act as external "stop signal," Whereas, growth hormones can be added as "start signal".

\section{CellCycle Checkpoints: The Checklist of the Cell}

Checkpoint is an important control point present in the cell cycle where stop and start signals can regulate the cell cycle. $\mathrm{G}_{1}$-restriction checkpoint decides whether the cell will enter into the $G_{0}$ phase or $S$ phase. S-checkpoint ensures the completion of DNA duplication(replication). $G_{2}$-DNA damage checkpoint checks preparedness of the cell for mitosis. M (metaphase)-spindle assembly checkpoint ensures that all sister chromatids are ready for separation.

$\mathrm{G}_{1}$-restriction point checks if the cell is fully mature, with ample space and adequate supply of nutrients, then the growth hormone will induce S-phase. Otherwise, if the cell maturation is incomplete with inadequate space, nutrients, and growth factors, then the cell is destined to enter $G_{0}$. At $S$-checkpoint by default, DNA is completely replicated with rising levels of DNA polymerase with its substrate (dNTPs) and cyclins. There is one important controlling mechanism that comes into play, termed as "replication licensing," otherwise known as "The Fidelity Check of Cell Cycle." It takes place 
by means of phosphorylatic degradation of origin binding protein, which is essential for the replication. It is the intrinsic property of an individual chromosome, which ensures single replication per each cell cycle. ${ }^{1,3,13-15}$ At $G_{2}$ checkpoint, there occur peak levels of cyclin with increased activation of mitosis-promoting factor (MPFkinase), which results in nuclear envelope disintegration. It also ensures that DNA replication in the S-phase has been completed successfully. It monitors the levels of growth factors and other related proteins as well. Then the $\mathrm{M}$-spindle assembly/integrity checkpoint operates at the end of M-phase in order to sense proper spindle integrity, precise chromosomal orientation in metaphase plate, and appropriate binding of spindle fibers to chromosomes. If any of these three found defective, then the integrity checkpoint stops the cell cycle progression, thereby preventing inappropriate "chromosomal sorting. ${ }^{16-19 "}$

\section{Cell Cycle Regulators: Cyclin and Cyclin-dependent Kinase}

Hunt, Hartwell and Nurse-Nobel Laureates from 2001-have discovered the key regulators of the cell cycle, CDK and cyclin.

\section{Cyclin}

Cyclin proteins are named so, due to their cyclic nature of production and degradation. They mainly trigger kinase activity. About 8 cyclins have been identified. Cyclin D, E, A, and B come to play serially during each cell cycle.

\section{Kinase}

These are the enzymes affecting the molecular activity of those proteins, which help a cell to pass through various stages of the cell cycle. The cyclin-CDK complex phosphorylates important target proteins and ensures the cell to proceed through the cell cycle.
On completion of the cell cycle, their levels decline quickly ${ }^{18,19}$ (Figs 3 and 4).

\section{Role of Cyclin: CDK Complex in Cancer}

Cancer or malignancy is the unchecked and uncontrolled multiplication of cells. Cell cycle regulator genes or the checkpoint genes are either misregulated or mutated in cancer, for example as seen in case of overexpression of cyclin D in cancer of breast, esophagus, liver, and a subset of lymphomas. However, amplification of the CDK4 gene leads to malignancies like melanomas, sarcomas, and glioblastomas. ${ }^{20-24}$

While cyclins activate the CDKs, their inhibitors (CDKIs) suppress the CDKs, exerting negative control over the cell cycle. The CDKIs are commonly mutated or suppressed in many human malignancies. For instance, germline mutations of p16 causes melanoma. Somatically acquired inactivation or deletion of p16 causes carcinoma pancreas, glioblastomas, cancer of esophagus, acute lymphocytic leukemia (ALL), non-small-cell lung carcinomas (NSCLC), soft-tissue sarcomas, and urinary bladder cancers. ${ }^{20-24}$

\section{Concept of Proto-oncogene and Tumor Suppressor Gene}

A proto-oncogene is a normal gene having the potential to become an oncogene by mutations; while oncogene is a gene that when mutated, gains a function or is over-expressed, abnormally resulting in the conversion of a normal cell into a cancer cell. It also causes a rise in gene transcription by kinases. These kinases are called transcription factors which usually affect $\mathrm{G}_{1} / \mathrm{S}$ transition, causing increased cyclin-CDK expression with decreased inhibition at an inappropriate time of cell cycle e.g., SRC, RAS, MYC, $B C L^{21,22}$ (Flowchart 1).
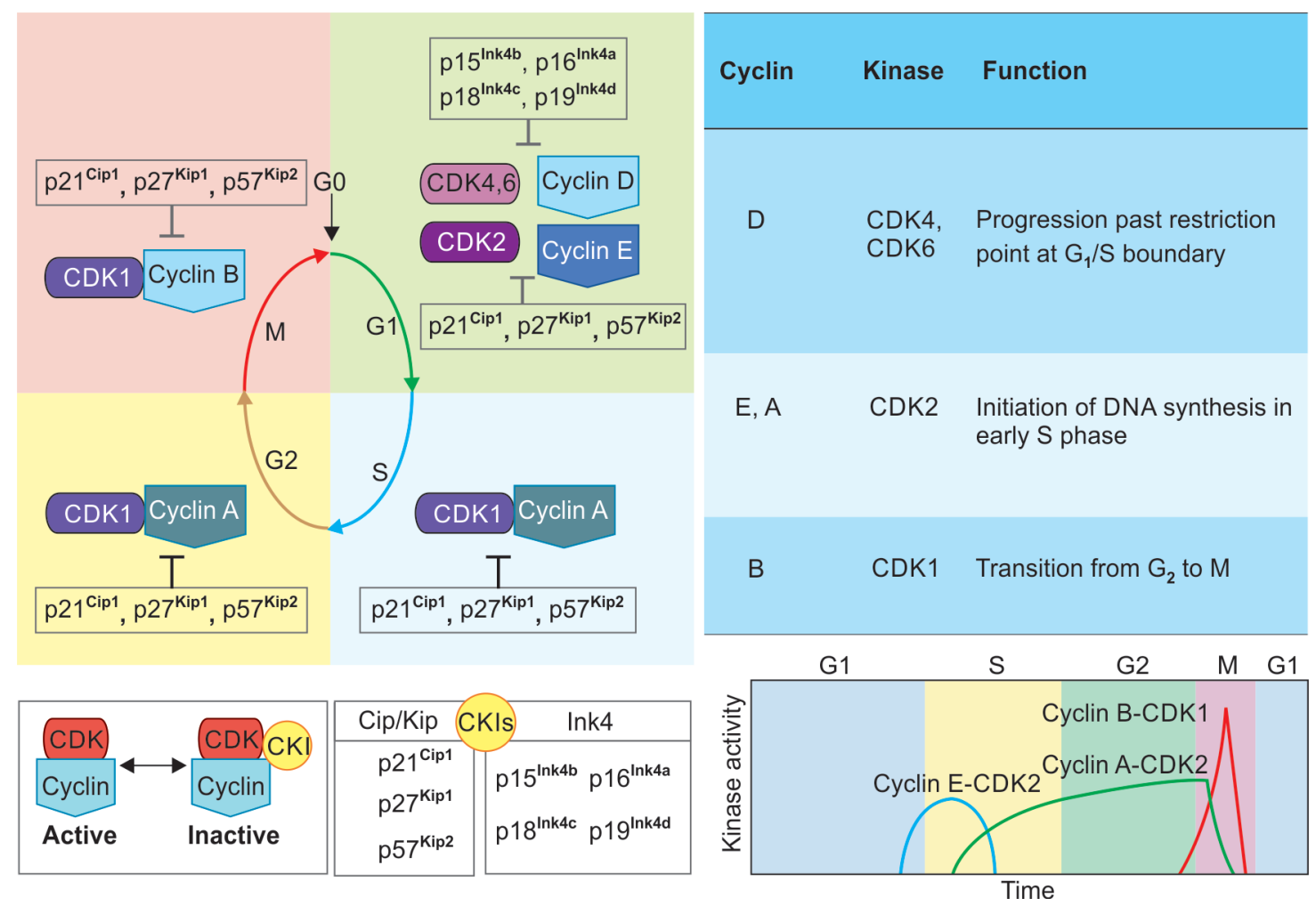

Fig. 3: Cyclin-dependent kinase and CKI 


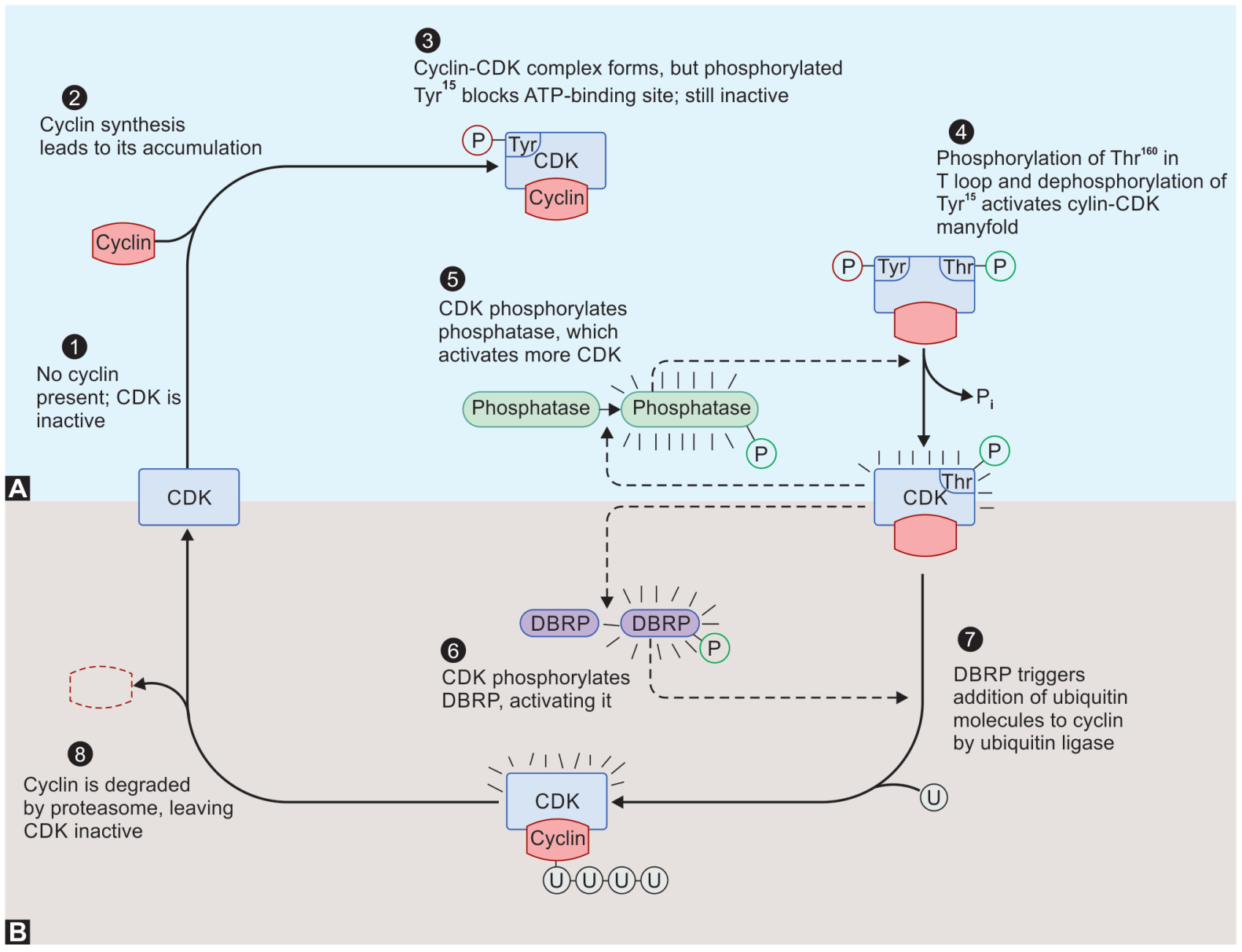

Fig. 4: Regulation of CDK by phosphorylation. DBRP, destruction box recognizing protein

Flowchart 1: Flow diagram showing proto-oncogene and tumor suppressor gene

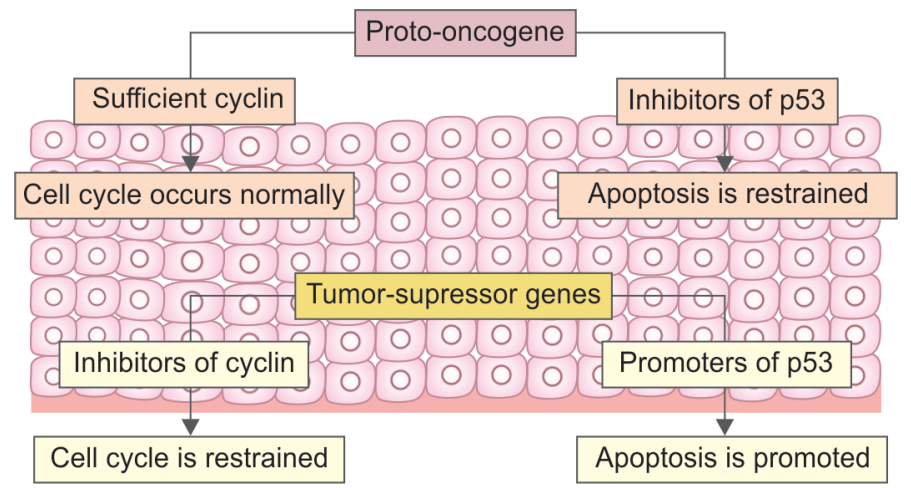

The checkpoint control proteins are coded by tumor suppressor genes (synonym: anti-oncogene). They prevent the entry of cells into S-phase in order to check the replication of damaged DNA, ultimately preventing abnormal cell division. Mutations in tumor suppressor genes are recessive but inheritable. So, both the copies must be knocked out to cause abnormal cellular division. They are principally involved in DNA repair, cell cycle control, and cell death (apoptosis) e.g., pRb, p53, APC, BRCA 1 and 2. ${ }^{22,23}$

Retinoblastoma protein (i.e., $p R b$ ), the product of the retinoblastoma $(R b)$ gene, which is a tumor suppressor gene, located on chromosome $13 q$ is a ubiquitously expressed nuclear phosphoprotein, that plays a key role in regulating the cell cycle. It acts by binding with $E 2 F$, a regulatory transcription factor, in order to have control over cell cycle progression. It controls the cell cycle progression at the transition from $\mathrm{G}_{1}$ to $S$ phase. It exists in the active hypophosphorylated state; upon binding to $E 2 F$, the cell enters into a quiescent state. $p R b$ gets inactivated by phosphorylation, thus phosphorylated $R b$ cannot bind to $E 2 F$, thereby cell cycle proceeds to $S$ phase. Germline mutations or loss of the $R b$ gene lead to retinoblastomas, osteosarcomas. Somatically acquired 


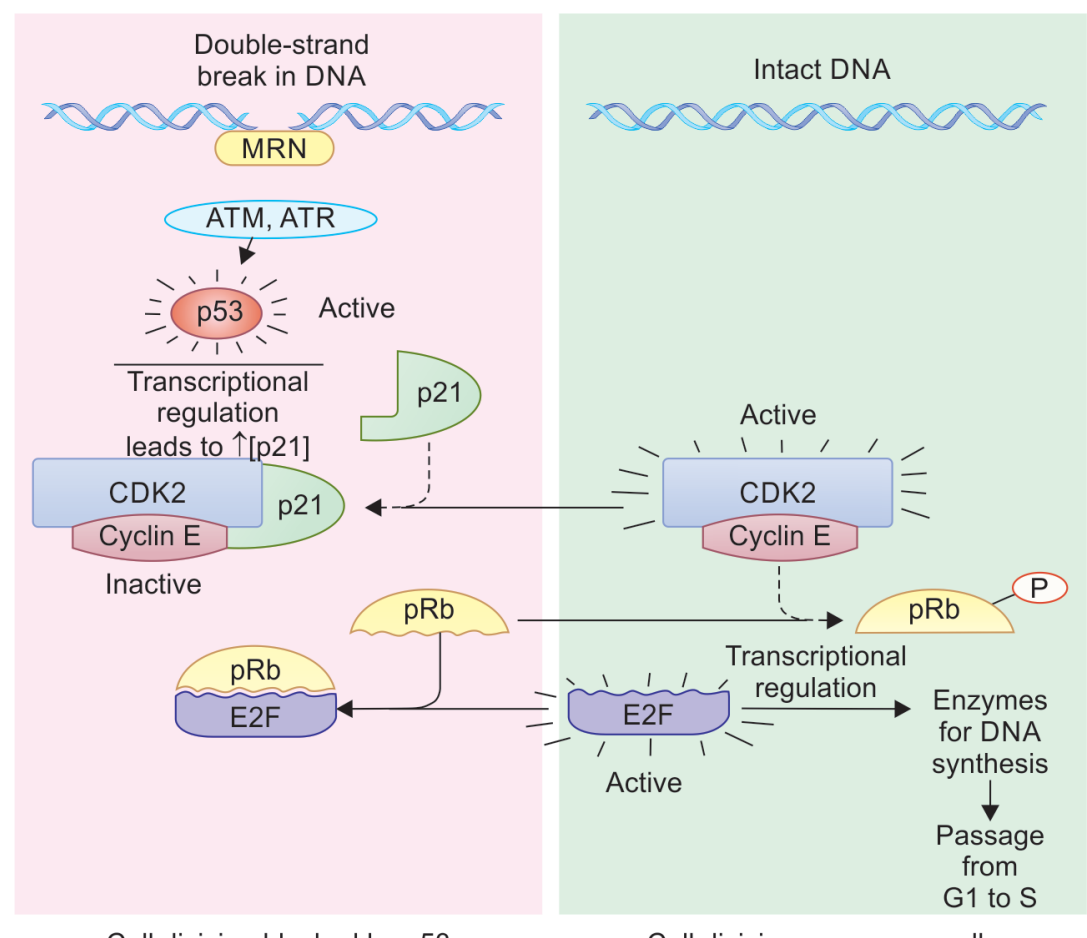

Fig. 5: Regulation of passage from $\mathrm{G}_{1}$ to $\mathrm{S}$ by phosphorylation of $p R b$

$R b$ gene mutations cause malignancies, such as glioblastomas, small-cell carcinoma of lung, breast cancer, and urinary bladder cancer $^{8,24-30}$ (Fig. 5).

\section{p53-'The Guardian of Genome'}

p53 gene is located on chromosome 17p and it is the most common $(80 \%)$ target for genetic alteration in tumors as suggested by genomic sequencing study. It mainly controls $G_{1}$ and $G_{2}$ checkpoints. p53 acts as a "molecular policeman" that prevents the propagation of genetically damaged cells through the cell cycle by acting as a DNA binding transcription factor. Homozygous loss of p53 occurs more or less in all types of cancer, such as cancers of the lung, colon, and breast, the three leading causes of cancer deaths. ${ }^{31-34}$

\section{Mechanism of Action of p53}

Various carcinogens and mutagens for example, heat, ionizing radiations, and toxic chemicals cause DNA damage. In normal cells with intact and functional p53, there occurs activation of p53 which upon binding with DNA, leads to the up-regulation of target genes. It results in the activation of p21 (CDK inhibitor), which in turn causes temporary arrest (quiescence) of the cell cycle at the $\mathrm{G}_{1}$ checkpoint By another GADD45 mediated mechanism, the cell tries to perform DNA repair. If the DNA repair is successfully attained, then the cell cycle resumes from quiescence and proceeds further. But if DNA repair fails, then the cell either undergoes permanent cell cycle arrest (senescence)with that damaged DNA or programmed necrobiosis (apoptosis). Thus, p53 inhibits neoplastic transformation by three aforesaid interlocking mechanisms ${ }^{31,35-37}$ (Flowchart 2).

These mechanisms operate in cells with intact p53. But when DNA damage happens in cells with p53 mutations or loss of p53, there occurs failure of activation of p53-dependent genes. So, the arrest of the cell cycle, as well as DNA repair, fail to take place in this situation, ultimately resulting in the formation of mutant cells. Furthermore, they expand with subsequent additional mutations, finally ending in the formation of a malignant tumor. ${ }^{36-39}$

As mentioned previously, the cell cycle is a series of coordinated events that comprise the process of DNA replication and cell division. There are two types of cell cycle control mechanisms. First, a cascade of protein phosphorylation that leads a cell from one stage to the next. Second, on the completion of critical events, there are several checkpoints to monitor the progress and delay progression to the next stage if found to be necessary. This checkpoint control is more supervisory as well as vigilant to sense flaws in the DNA replication and segregation. ${ }^{40}$

The connection between the cell cycle and cancer is relevant. As cell cycle controls proliferation, inappropriate cell proliferation leads to cancer. Most of the carcinogenic agents cause DNA damage, by introducing errors into DNA during the cell cycle or during repair. ${ }^{40,41}$

\section{Carcinogenesis (Flowchart 3)}

This genetic alteration contributing to cancer development is termed as "mutation". Mutation in the genome of somatic cells leads to the gain of function, activating growth-promoting oncogenes, or inactivating tumor suppressor genes. This change leads to unregulated cell proliferation and clonal expansion. Also, loss of function in gene-regulating apoptosis will decrease apoptosis, ultimately resulting in clonal expansion. Furthermore, additional mutation, angiogenesis, and compromised immune surveillance 
Flowchart 2: Role of p53 in the prevention of carcinogenesis

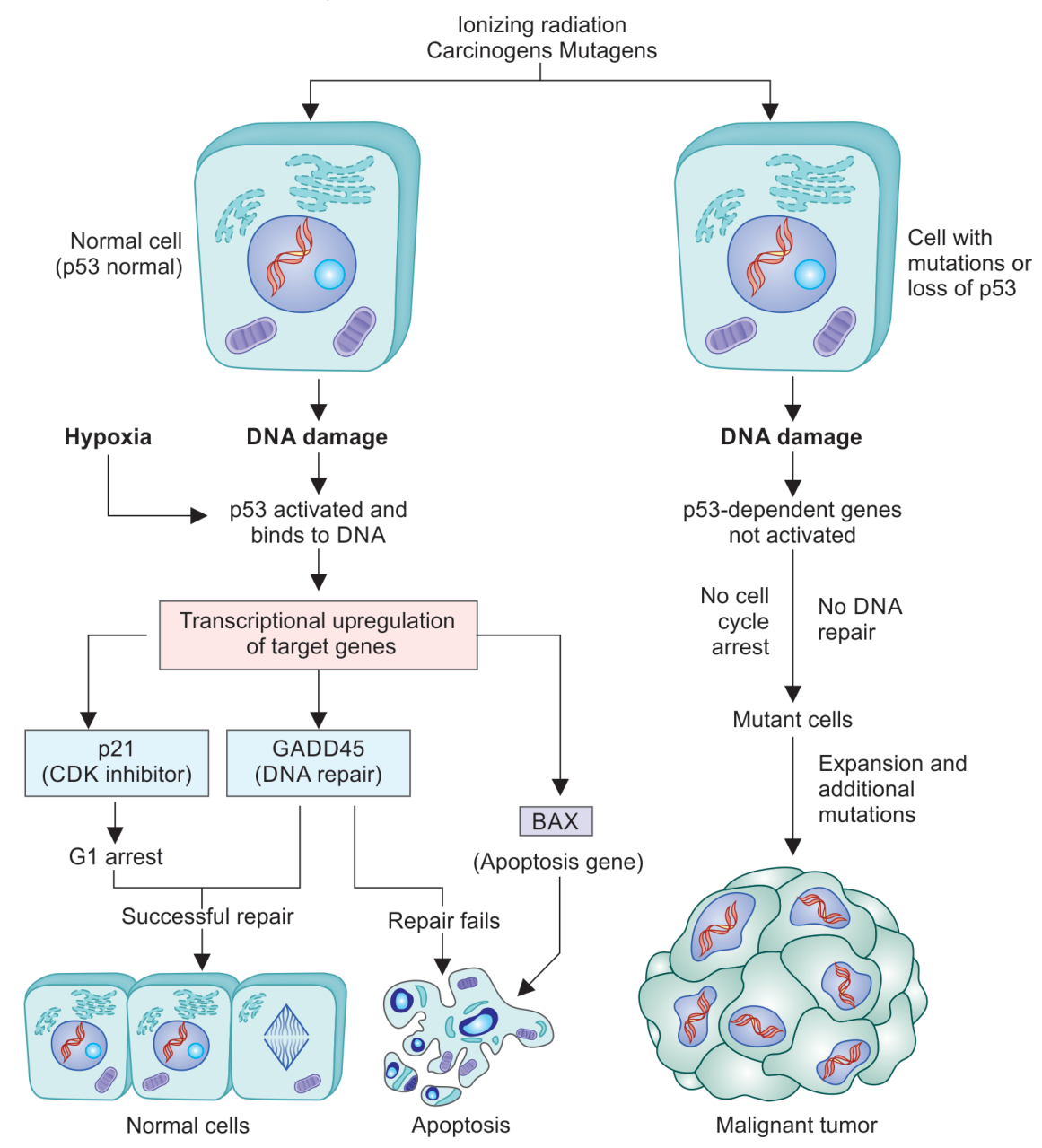

Flowchart 3: Flow diagram showing progression of carcinogenesis

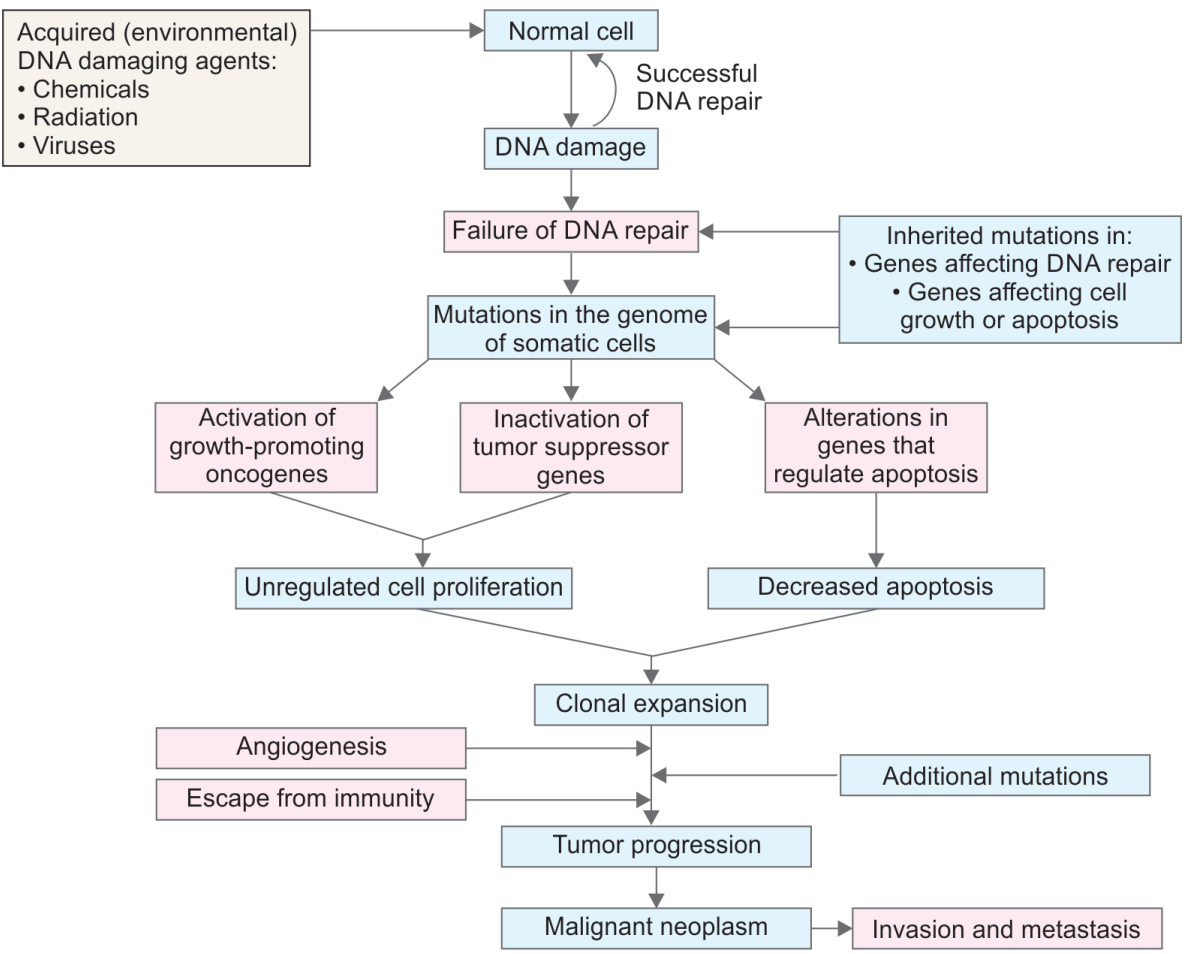


mechanism will confer metastatic potential of further tumor cell progression to malignant neoplasm. ${ }^{40,41}$

\section{Cancer: Six Hallmarks (Fig. 6)}

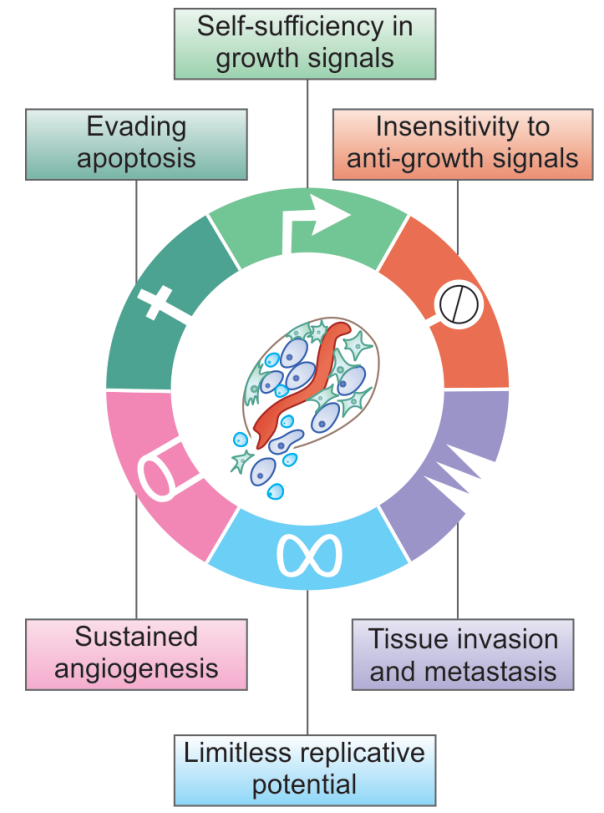

Fig. 6: Cancer-6 hallmarks

\section{Conclusion}

In this study, the essential principles behind the cell cycle checkpoints have been described in detail. The feature of detecting a defect within the cell cycle program, which in turn sends signals forward to change the oscillation of CDK activity in order to further control the cell cycle events. Some aspects of checkpoint signaling still remain to be clearly understood either as the basic underlying principle or within the context of diseases. Undoubtedly, the hidden aspects of checkpoint signaling can be further explored with the help of an ever-growing arsenal of highly sophisticated experimental tools and techniques, which will enable us to get a more clear and complete picture of the remarkable fidelity of the cell cycle.

\section{References}

1. Hunter T, Pines J. Cyclins and cancer. II: Cyclin D and CDK inhibitors come of age. Cell 1994;79(4):573-582. DOI: 10.1016/00928674(94)90543-6.

2. Morgan DO. Principles of CDK regulation. Nature (London) 1995;374(6518):131-134. DOI: 10.1038/374131a0.

3. Nasmyth K. Viewpoint: putting the cell cycle in order. Science 1996;274(5293):1643-1645. DOI: 10.1126/science.274.5293.1643.

4. Elledge SJ.Cell cycle checkpoints: preventing an identity crisis. Science 1996;274(5293):1664-1672. DOI: 10.1126/science.274.5293.1664.

5. Sherr CJ. Cancer cell cycles. Science 1996;274(5293):1672-1677. DOI: 10.1126/science.274.5293.1672.

6. Jackson SP, Bartek J. The DNA-damage response in human biology and disease. Nature 2009;461(7267):1071-1078. DOI: 10.1038/ nature08467.

7. Curtin NJ. DNA repair dysregulation from cancer driver to therapeutic target. Nat Rev Cancer 2012;12(12):801-817. DOI: 10.1038/nrc3399.
8. Nelson DL, Cox MM. Lehninger principle of biochemistry. 7th ed., 2017. pp. 476-484.

9. Maller JL. MPF and cell cycle control. Adv Second Messenger Phospho Protein Res 1990;24:323-328.

10. Masui Y. From oocyte maturation to the in vitro cell cycle: the history of discoveries of maturation-promoting factor (MPF) and cytostatic factor (csf). Differentiation 2001;69(1):1-17. DOI: 10.1046/j.14320436.2001.690101.x

11. Killander D, Zetterberg A. A quantitative cytochemical investigation of the relationship between cell mass and initiation of DNA synthesis in mouse fibroblasts in vitro. Exp Cell Res 1965;40(1):12-20. DOI: 10.1016/0014-4827(65)90285-5.

12. Killander D, Zetterberg A. Quantitative cytochemical studies on interphase growth. I. Determination of DNA, RNA and mass content of age determined mouse fibroblasts in vitro and of intercellular variation in generation time. Exp Cell Res 1965;38(2):272-284. DOI: 10.1016/0014-4827(65)90403-9.

13. Wan G, Mathur R, Hu X, et al. miRNA response to DNA damage. Trends Biochem Sci 2011;36(9):478-484. DOI: 10.1016/j.tibs.2011.06.002.

14. Mathur R, Chandna S, Kapoor PN, et al. Peptidyl prolyl isomerase, Pin1 is a potential target for enhancing the therapeutic efficacy of etoposide. Curr Cancer Drug Targets 2011;11(3):380-392. DOI: 10.2174/156800911794519761.

15. Wan G, Mathur R, Hu X, et al. Long non-coding RNA ANRIL (CDKN2B-AS) is induced by the ATM-E2F1 signaling pathway. Cell Signal 2013;25(5):1086-1095. DOI: 10.1016/j.cellsig.2013.02.006.

16. Kastan MB, Bartek J. Cell-cycle checkpoints and cancer. Nature 2004;432(7015):316-323. DOI: 10.1038/nature03097.

17. Bartek J, Lukas J. DNA damage checkpoint: from initiation to recovery or adaptation. Curr Opin Cell Biol 2007;19(2):238-245. DOI: 10.1016/j. ceb.2007.02.009.

18. Matsuoka S, Huang M, Elledge SJ. Linkage of ATM to cell cycle regulation by the Chk2 protein kinase. Science 1998;282(5395):18931897. DOI: 10.1126/science.282.5395.1893.

19. Falck J, Mailand N, Syljuåsen RG, et al. The ATM-Chk2-Cdc25A checkpoint pathway guards against radioresistant DNA synthesis. Nature 2001;410(6830):842-847. DOI: 10.1038/35071124.

20. Harper JW, Adami GR, Wei N, et al. The p21 CDK-interacting protein Cip1 is a potent inhibitor of G1 cyclin-dependent kinases. Cell 1993;75(4):805-816. DOI: 10.1016/0092-8674(93)90499-g.

21. McDuff FK, Turner SD. Jailbreak: oncogene-induced senescence and its evasion. Cell Signal 2011;23(1):6-13. DOI: 10.1016/j. cellsig.2010.07.004.

22. Sun W, Yang J. Functional mechanisms for human tumor suppressors. J Cancer 2010;1:136-140. DOI: 10.7150/jca.1.136.

23. Vattemi E, Claudio PP. Tumor suppressor genes as cancer therapeutics. Drug News Perspect 2007;20(8):511-520. DOI: 10.1358/ dnp.2007.20.8.1157613.

24. Jiao W, Lin HM, Datta J, et al. Aberrant nucleocytoplasmic localization of the retinoblastoma tumor suppressor protein in human cancer correlates with moderate/poor tumor differentiation. Oncogene 2008;27(22):3156-3164. DOI: 10.1038/sj.onc.1210970.

25. Jiao W, Datta J, Lin HM, et al. Nucleocytoplasmic shuttling of the retinoblastoma tumor suppressor protein via Cdk phosphorylationdependent nuclear export. J Biol Chem 2006;281(49):38098-38108. DOI: $10.1074 / j b c . M 605271200$.

26. Ren S, Rollins BJ. Cyclin C/cdk3 promotes Rb-dependent $\mathrm{G} 0$ exit. Cell 2004;117(2):239-251. DOI: 10.1016/s0092-8674(04)00300-9.

27. Johnson BR, Nitta RT, Frock RL, et al. A-type lamins regulate retinoblastoma protein function by promoting subnuclear localization and preventing proteasomal degradation. Proc Natl Acad Sci USA 2004;101(26):9677-9682. DOI: 10.1073/pnas.0403250101.

28. Angus SP, Solomon DA, Kuschel L, et al. Retinoblastoma tumor suppressor: analyses of dynamic behavior in living cells reveal multiple modes of regulation. Mol Cell Biol 2003;23(22):8172-8188. DOI: $10.1128 / \mathrm{mcb} .23 .22 .8172-8188.2003$. 
29. DeMichele A, Clark AS, Tan KS, et al. CDK 4/6 inhibitor palbociclib (PD0332991) in Rb+ advanced breast cancer: phase Il activity, safety, and predictive biomarker assessment. Clin Cancer Res 2015;21(5):9951001. DOI: 10.1158/1078-0432.CCR-14-2258.

30. Leiderman YI, Kiss S, Mukai S. Molecular genetics of RB1-the retinoblastoma gene. Semin Ophthalmol 2007;22(4):247-254. DOI: 10.1080/08820530701745165.

31. el-Deiry WS, Tokino T, Velculescu VE, et al. WAF1, a potential mediator of p53 tumor suppression. Cell 1993;75(4):817-825. DOI: 10.1016/00928674(93)90500-p.

32. Shieh SY, Ikeda M, Taya Y, et al. DNA damage-induced phosphorylation of p53 alleviates inhibition by MDM2. Cell 1997;91(3):325-334. DOI: 10.1016/s0092-8674(00)80416-x.

33. Allday MJ, Inman GJ, Crawford DH, et al. DNA damage in human B cells can induce apoptosis, proceeding from G1/S when p53 is transactivation competent and G2/M when it is transactivation defective. EMBO J 1995;14(20):4994-5005. DOI: 10.1002/j.14602075.1995.tb00182.x.

34. Canman CE, Lim DS, Cimprich KA, et al. Activation of the ATM kinase by ionizing radiation and phosphorylation of $\mathrm{p} 53$.
Science 1998;281(5383):1677-1679. DOI: 10.1126/science.281. 5383.1677.

35. Nayak SK, Panesar PS, Kumar H. p53-Induced apoptosis and inhibitors of p53. Cur Med Chem 2009;16(21):2627-2640. DOI: 10.2174/092986709788681976.

36. Vousden KH, Lu X. Live or let die: the cell's response to p53. Nat Rev Cancer 2002;2(8):594-604. DOI: 10.1038/nrc864.

37. Soddu S, Sacchi A. P53 role in DNA repair and tumorigenesis. J Exp Clin Cancer Res 1997;16(3):237-242.

38. Rufini A, Tucci $P$, Celardo l, et al. Senescence and aging: the critical roles of p53. Oncogene 2013;32(43):5129-5143. DOI: 10.1038/ onc.2012.640.

39. Riley T, Sontag E, Chen P, et al. Transcriptional control of human p53-regulated genes. Nat Rev Mol Cell Biol 2008;9(5):402-412. DOI: 10.1038/nrm2395

40. Balmain A, Gray J, Ponder B. The genetics and genomics of cancer. Nat Genet 2003;33(Supp I):238-244. DOI: 10.1038/ng1107.

41. Esteller M. Epigenetics in cancer. N Engl J Med 2008;358(11):1148-1159. DOI: $10.1056 /$ NEJMra072067. 